\title{
Taopatch $^{\circledR}$ combined with home-based training protocol to prevent sedentary lifestyle and biochemical changes in MS patients during COVID-19 pandemic
}

Alessandra Amato (1)\#, Giuseppe Messina (1) \#, Kaltrina Feka (1), Diego Genua (1) Paolo Ragonese (2), Dorota Kostrzewa-Nowak (3,4), Francesco Fischetti (5), Angelo Iovane (1), Patrizia Proia (1)

(1) Department of Psychological, Pedagogical and Educational Sciences, Sport and Exercise Sciences Research Unit, University of Palermo, Italy; (2) Department of Biomedicine, Neurosciences and Advanced Diagnostics (Dipartimento di Biomedicina, Neuroscienze e Diagnostica avanzata) (Bi.N.D.), University of Palermo, Italy; (3) Faculty of Physical Education and Health Promotion, University of Szczecin, Szczecin, Poland; (4) Institute of Physical Culture Sciences, University of Szczecin, Szczecin, Poland; (5) Department of Basic Medical Sciences, Neuroscience and Sense Organs, School of Medicine, University of Study of Bari, Italy. "These authors contributed equally

This article is distributed under the terms of the Creative Commons Attribution Noncommercial License (CC BY-NC 4.0) which permits any noncommercial use, distribution, and reproduction in any medium, provided the original author(s) and source are credited.

\begin{abstract}
In Multiple sclerosis (MS) it is important to preserve the residual physiological functions of subjects. The aim of the present study was to investigate the influence of nanotechnological device treatment combined with home-based training program (TP) on lactate level, hand grip strength and cervical mobility on MS patients. Seventeen MS patients were enrolled in the study and randomly assigned to an experimental group (EG) in which the Taopatch ${ }^{\circledR}$ nanotechnological device was applied or to a control group (CG). All the participants carried out a cervical range of motion (1) assessment and the hand grip test at baseline (T0) and after TP (T1), also investigating the lactate levels to figure out if there could be a correlation with the possible changes in the investigated parameters. The results showed no significant differences in both groups for ROM. As regards the hand grip test, EG showed a statistically significant improvement on strength for both hands, dominant $(p=0.01)$ and non-dominant $(p=0.04)$, while the CG showed an improvement only for the non-dominant hand $(\mathrm{p}=0.001)$. No correlation was found between baseline lactate level and cervical ROM change. We can definitely conclude that exercise and Taopatch ${ }^{\circledR}$ can help to improve and maintain hand strength in MS subjects and also can prevent sedentary lifestyle during the COVID-19 pandemic time. These are preliminary results that need further investigations, possibly increasing sample size and lengthening time of intervention.
\end{abstract}

Key Words: Home-based training program; cervical range of motion; lactate; nanotechnologybased device; hand grip test; Taopatch ${ }^{\circledR}$; light therapy.

Eur J Transl Myol 31 (3): 9877, 2021 doi: 10.4081/ejtm.2021.9877

Multiple Sclerosis (MS) is a chronic disabling disease of the central nervous system (CNS) of unknown aetiology. ${ }^{1}$ In this disease the CNS is affected by an immune-mediated inflammatory disease followed by a demyelination with consequent axonal damage. ${ }^{2}$ This disabling state affects the musculoskeletal system impairing physical characteristics. ${ }^{3}$ In fact, among the symptoms that MS patients experience, there are fatigue, weakness, impaired mobility, with related physical functioning scores which affect the quality of life. ${ }^{4}$ It has been demonstrated that specific physical training protocol, such us proprioceptive training, can improve the quality of life in these subjects through the improvement of some impaired abilities. ${ }^{5}$ However, these protocols alone seem to have no prolonged effects over time to improve balance, range of motion or postural control in these subjects. ${ }^{1}$ For this reason, myofascial release (MFR) has been proposed as a method that improves the range of motion and the quality of movements. ${ }^{6}$ However, there are obvious limitations for 
MFR being an operator sensitive technique. Alternatively, it emerged the possibility to use a very similar but simpler technique, the self-myofascial release (SMFR), which can be self-applied individually. ${ }^{7}$ Furthermore, change in lactate concentration are related to various physiological and pathological conditions such as MS in which is already known that there is an increase of lactate levels. ${ }^{8}$ In general, in research experience the influence of several biomechanical devices, as occlusal splints and foot orthoses, on many physical features have been investigated reporting conflicting results. $^{9-12}$ Although the use of nanotechnological devices is growing in different healthcare application, only a few research groups have studied the role of a nanotechnological device on physical features. ${ }^{13} \mathrm{~A}$ medical device, recently developed, that uses nanotechnology is the Taopatch ${ }^{\circledR}$ (Tao Technologies, Italy). This device acts through light therapy thanks to the use of quantum dots. These quantum dots are nanocrystals excited with the heat and the sunlight that will be transformed into near-far infrared and ultraviolet light that can have beneficial effects on the human body. ${ }^{13}$ Taopatch ${ }^{\circledR}$ appears as a circular microchip, with $16 \mathrm{~mm}$ diameter and less than $1 \mathrm{~mm}$ thick. The device is applied to the skin with the aid of tape. The coating is in hypoallergenic plastic material with inside a mixture of nanotechnology, the main components are nanocrystals called quantum dots, of the upconverting nanocrystals.

In a recent study, Carbonari et al have highlighted changes in strength and body balance using this nanotechnological device by detecting athlete's performance. In fact, Taopatch ${ }^{\circledR}$ device has improved strength and balance performance increasing the maximum tension of the affected muscles; the electromyography was used to detect changes in the activity of the postural muscles. ${ }^{13}$ Lomeo et al. (2019), ${ }^{9}$ investigated the effect of Taopatch ${ }^{\circledR}$ in subjects with MS and showed that the use of these devices can improve and prolong the effect on proprioception, balance, mouvements of the affected limbs and this can be extremely helpful for these patients. They also observed (SF-36 Questionnaire) an improvement in physical and emotional conditions of the patients. ${ }^{9}$ In addition, nanotechnology has been shown to be useful for several purposes including performance and posture improvements and injury recovery. ${ }^{13}$ It is now known that exercise improves physical health but also the quality of life and this need is accentuated in this period of forced sedentary lifestyle due to the pandemic situation, ${ }^{14,15}$ and especially in subjects with various pathologies, physical activity can be the key factor to improve quality of life; in particular, individuals with MS have a tendency to be sedentary due to the difficulty of following a rehabilitation program in hospitals or authorized centers. ${ }^{16}$ This is due to fatigue due to illness, drug treatment as well as depression and social isolation also due to the consequences of the pandemic caused by COVID-19. The aim of our study was to evaluate if
Taopatch $^{\circledR}$, combined with a home-based protocol of proprioceptive and joint mobility training together with a SMFR treatment, can induce a change in biochemical biomarkers like lactate as well as strength and cervical ROM in MS patients.

\section{Materials and Methods}

\section{Patients}

Seventeen subjects (age: 51,24 $\pm 10,66$; height: $170,65 \pm 10,42$; weight: $76,47 \pm 12,30$ ) with relapsingremitting MS (RR-MS) with an Expanded Disability Status Scale (EDSS) between 3.5-5.5 were enrolled in the study by physical medicine and rehabilitation center "Vitality" from Vita, Sicily, Italy. Subjects were randomly assigned to the Experimental Group (EG; n=9) or Control Group (CG; $\mathrm{n}=8$ ) who performed a Training Program (TP) with (EG) or without (CG) Taopatch ${ }^{\circledR}$.

The study was conducted according to the guidelines of the Declaration of Helsinki, and approved by the Ethics Committee of The Palermo 1, decree N 7/2016 Policlinico Giaccone Hospital, Palermo, Italy. Informed written consent was obtained from all participants of the study. An anamnestic examination was carried out by specialized medical personnel before starting the study.

\begin{abstract}
Assessments
Participants of both groups performed a cervical ROM and a hand grip test at baseline $\left(\mathrm{T}_{0}\right)$ and after a training program period (T1). In addition, lactate level was evaluated in all participants at baseline (Accutrend ${ }^{\circledR}$ Plus, Roche). Cervical ROM was measured with an accelerometer (Moover ${ }^{\circledR}$; Sensor Medica ${ }^{\circledR}$; Guidonia Montecelio, Roma, Italia) placed in the center of the forehead with a band. Subjects performed a left (L) and right $(\mathrm{R})$ rotation; inclination ( $\mathrm{L}$ and $\mathrm{R}$ ) and a flexion and an extension of the cervical segment. Each movement was performed starting from an upright position with the head in line with the body. Handgrip test (KERN MAP Version 1.2 08/2012, Hand Grip Dynamometer) was performed three time each side and the best result of $\mathrm{L}$ and $\mathrm{R}$ hand was considered to data analysis.
\end{abstract}

\section{Training Program}

The TP was composed of 20 sessions of 1 hour carried out twice a week, it included proprioceptive and joint mobility exercises and a self-myofascial release treatment, in particular they performed:

- About 5 minutes of circuit gait training on the platform (forward, backward, sideways, on toes with eyes open and eyes closed) and go up and down three steps.

- 3 exercises (2 minutes each exercise) of pelvic mobilization and breathing sitting on the fit ball: hip bone anteversion; hip bone retroversion; hip bone rotation and lateralization.

- 20 minutes of stationary bicycle Fitness minibike (Roten bi-bike), an automatic system for leg, miming 


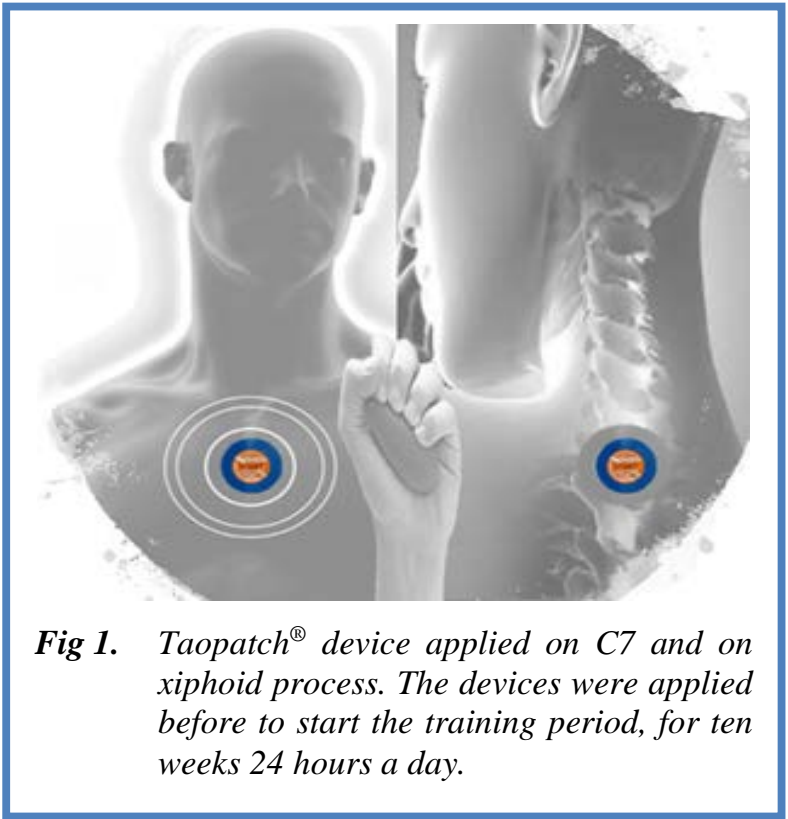

a bicycle, which allows passive, active or assisted mobilization for patients with MS.

- As concerns proprioceptive handgrip exercise, the patients performed about 15 minutes of the protocol described in Liu et al., 2018. ${ }^{17}$ In summary the subjects performed 25 repetitions of the grip exercise with both hands (alternating the side) using an elastic ball; each repetition consisted in squeezing the elastic ball for 10 seconds, then relax for 10 seconds.

- 15 minutes of SMFR treatment following the protocol described from Amato et al. ${ }^{18}$

During each training session, a nanotechnological device (Taopatch $^{\circledR}$; Tao Technologies srl) was applied only to EG, as showed in Figure 1, positioned in two different points: below C7 posteriorly and on the xiphoid process anteriorly. The devices were applied before starting the training period (ten weeks, 24 hours a day).

\section{Statistical analysis}

The Kolgomorov-Smirnov test was used to check for normal distribution. Student t-tests were used to compare the baseline characteristics of the two groups. Changes between baseline and T1 within the groups were analyzed by paired t-test. Within-group changes were calculated as percentage changes. Unpaired t-test were used to compare these differences in the two groups. The correlations between handgrip test and lactate level were statistically evaluated using Pearson correlation (PC) tests. All tests were two-tailed, and a 5\% probability level was considered significant. We used SPSS (IBM SPSS Statistics 23) for statistical analysis.

\section{Results}

The Kolgomorov-Smirnov test shows that all data are normally distributed. Table 1 describes the values of the variables assessed at $\mathrm{T}_{0}$ for CG and EG. The unpaired TTest highlighted that only for handgrip test there were
Table 1. Anthropometric, cervical ROM and strength variables at baseline for control and experimental group.

\begin{tabular}{|c|c|c|c|}
\hline \multirow[t]{2}{*}{ Variables } & \multirow{2}{*}{$\begin{array}{l}\text { Control } \\
(n=8)\end{array}$} & Group & Experimental Group ( $n=9$ ) \\
\hline & & Mean \pm SD & Mean \pm SD \\
\hline Age & & $44,75 \pm 7,91$ & $50,89 \pm 12,04$ \\
\hline Height & & $166,22 \pm 11,63$ & $175,63 \pm 6,32$ \\
\hline Weight & & $74 \pm 12,23$ & $79,25 \pm 12,59$ \\
\hline ROT L $\left(^{\circ}\right)$ & & $69,66 \pm 5,87$ & $66,16 \pm 13,31$ \\
\hline ROT R $\left(^{\circ}\right)$ & & $67,12 \pm 9,34$ & $59,86 \pm 16,28$ \\
\hline ROTtot $\left({ }^{\circ}\right)$ & & $136,80 \pm 12,89$ & $126 \pm 28,92$ \\
\hline $\operatorname{INC~L~}\left(^{\circ}\right)$ & & $41,38 \pm 12,80$ & $35,08 \pm 9,52$ \\
\hline INC R $\left(^{\circ}\right)$ & & $36,90 \pm 6,98$ & $33,33 \pm 13,21$ \\
\hline $\operatorname{INCtot}\left({ }^{\circ}\right)$ & & $78,30 \pm 17,83$ & $68,42 \pm 20,85$ \\
\hline Flex $\left(^{\circ}\right)$ & & $54,40 \pm 11,58$ & $49,31 \pm 14,06$ \\
\hline $\operatorname{Extn}\left({ }^{\circ}\right)$ & & $57,70 \pm 15,23$ & $54,30 \pm 16,66$ \\
\hline Flex-extn $\left({ }^{\circ}\right)$ & & $112,09 \pm 20,90$ & $103,61 \pm 28,56$ \\
\hline Handgrip R ( $\mathrm{k}$ & kg) & $29,51 \pm 7,21$ & $19,10^{\#} \pm 8,53$ \\
\hline Handgrip L (k & kg) & $29,17 \pm 6,62$ & $18,91^{\#} \pm 9,20$ \\
\hline
\end{tabular}

Flex: flexion; Extn: extension; R: right; L: left; ROT: rotation; INC: inclination. \# Significance between-group $(p<0.05)$. SD Standard Deviation

significant differences between groups at baseline. $\mathrm{R}$ hand (Kg): $19.10 \pm 8,53$ (EG); $29.51 \pm 7.21$ (CG), p<0.05;

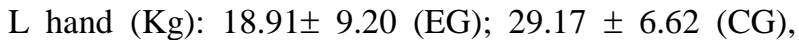
$\mathrm{p}<0.05$. No significant differences between groups were detected at $\mathrm{T}_{0}$ for all the other parameters investigated $(p>0,05)$. After training program intervention there were no significant differences between $T_{0}$ and $T_{1}$ in both groups in cervical ROM evaluations. Regarding strength assessment, hand grip test showed a change between $\mathrm{T}_{0}$

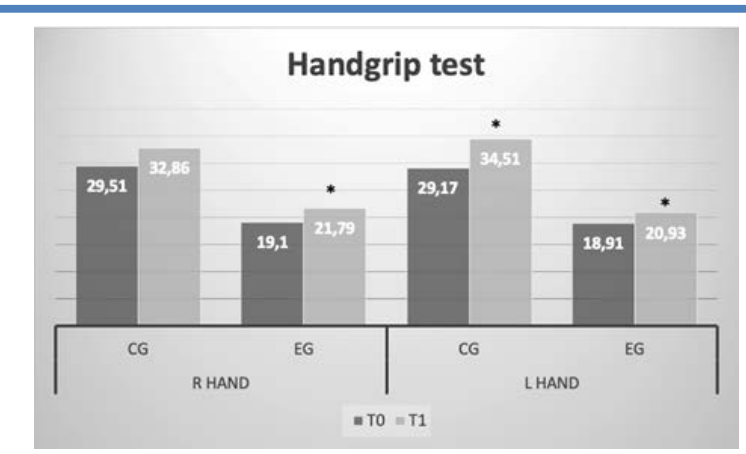

Fig 2. Baseline (T0) and post exercise program period (T1) values of strength variables of control (CG) and experimental (EG). R: right; L: left; *Significant within-group difference between T0 and T1 $(p<0.05)$. 
Table 2. Pearson correlation coefficients (PC) and significances $(S)$ are shown in the table between handgrip test and basal lactate levels.

\begin{tabular}{|c|c|c|c|c|}
\hline & \multicolumn{4}{|c|}{ Lactate Baseline } \\
\hline & \multicolumn{2}{|c|}{ Handgrip test T0 } & \multicolumn{2}{|c|}{ Handgrip test T1 } \\
\hline & PC & $\mathrm{S}$ & PC & $\mathrm{S}$ \\
\hline \multicolumn{5}{|c|}{ Control Group } \\
\hline Handgrip R & $-0,59$ & 0,12 & $-0,47$ & 0,24 \\
\hline Handgrip L & $-0,033$ & 0,94 & $-0,02$ & 0,97 \\
\hline \multicolumn{5}{|c|}{ Experimental Group } \\
\hline Handgrip R & $-0,13$ & 0,75 & $-0,16$ & 0,69 \\
\hline Handgrip L & $-0,46$ & 0,21 & $-0,43$ & 0,25 \\
\hline
\end{tabular}

and $\mathrm{T}_{1}$ in both groups; in detail as regard the experimental group there were an increase of $10.70 \%$ in left hand $\left(\mathrm{T}_{0}\right.$ $18.91 \pm 9.20$ vs $\left.\mathrm{T}_{1} 20.93 \pm 8.80 ; \mathrm{p}<0,05\right)$ and of $14.08 \%$ in right hand $\left(\mathrm{T}_{0} 19.10 \pm 8.53\right.$ vs $\mathrm{T}_{1} 21.79 \pm 8.80$; $\mathrm{p}<$ $0.05)$. Figure 2 shows that in control group instead there was an increase of $18 \%$ only in left hand $\left(\mathrm{T}_{0} 29.18 \pm 6,62\right.$ vs $\mathrm{T}_{1} 34.51 \pm 6.68 ; \mathrm{p}<0.05$ ). Starting from the lactate level baseline (CG $1.36 \pm 0.37$ vs EG $1.44 \pm 0.53$ ), no correlation was found between handgrip evaluations and lactate level. Table 2 shows the Pearson's correlation coefficients for each variable.

\section{Discussion}

The aetiology of Multiple Sclerosis is still unknown. Many factors play a role in the onset of the pathology, that also change gait and balance abilities. ${ }^{19}$ Certainly, exercise can help to manage MS symptoms, to prevent some complications, to increase strength, mobility, static and dynamic balance and consequently improving quality of life. ${ }^{5}$ However, to date, all medical, surgical and physical rehabilitation therapies have not shown lasting benefits over time. Taopatch ${ }^{\circledR}$ abilities to improve movement, posture and balance have been demonstrated, ${ }^{13,20}$ the ultra-low-level electromagnetic field generated by the nanotechnology-based devices may provide an improvement to the input system or central modulation resulting in an improved muscle tone and, thus, an enhanced posture control. ${ }^{21}$ It has recently been shown that also in subjects with MS, these devices can induce improvement on proprioception, ROM and balance. ${ }^{9}$ For these reasons we hypothesized that the use of this device combined with physical activity performed at home could have effects on functional impairments in MS patients. We enrolled in our study 17 MS patients split in 2 groups that both performed PA but just one, the experimental group, wore the Taopatch ${ }^{\circledR}$ devices. The results obtained didn't highlighted any statistically significant changes in all cervical ROM variables analyzed $(\mathrm{p}>0.05)$
Considering that other symptoms like muscle weakness can occur especially in asymmetrically way in persons with MS, hence a difference between both hands can be expected. It has been assumed that non-dominant arm is likely to be more impaired than the dominant arm, because of reduced use in daily life, given decreased functionality, ${ }^{22}$ and not for the features of the disease (because the fatigue in MS patients have a central origin). ${ }^{23}$ In fact, Severijns et al in their study showed that hand grip strength in people with multiple sclerosis is not influenced by hand dominance. ${ }^{24}$ Therefore, the aim of our study was to understand if the association between TP and Taopatch ${ }^{\circledR}$ can reduce the progression of muscle weakness through the improvement of the upper limb strength. In this way this should contribute to improve the quality of life of the patients by maintaining autonomy and facilitating some of the daily actions. Our results showed in the handgrip test a statistically significant increase in the experimental group, in both hands: for right hand $14.08 \%$ of increase $(\mathrm{p}=0.01)$ with a gain of $2.69 \mathrm{Kg}$ and for left hand $10,70 \%$ of increase $(\mathrm{p}=0.04)$ with a gain of $2.02 \mathrm{Kg}$. It's already published a change of $5.5 \mathrm{~kg}$ in handgrip score reliably indicate a true change in functional abilities that are the actual or potential capacities of an individual to perform the activities and tasks that can be normally expected. ${ }^{25}$ Indeed, this provides hints for future investigations and since hand strength is frequently impaired in individuals with MS, further studies are warranted to establish using the hand grip as a clinical test and to monitor important change in disease. $^{22,24,26-28}$ In the future it will be interesting to associate the result of handgrip test with a questionnaire measuring patient-perceived difficulties in performing manual activities of daily living such as the ABILHAND questionnaire, validated in patients with $\mathrm{MS} .{ }^{29}$ In this way, we could investigate the impact of hand function on home and work life and their perception of change in function over time.

In conclusion, association between proprioceptive, joint mobility exercise and SMFR with Taopatch ${ }^{\circledR}$ device can help to improve and to maintain hand strength in MS subjects by delaying the onset of hand dysfunctions and by facilitating manual activities of daily living. It also works to prevent sedentary lifestyle due to COVID-19 pandemic.
List of acronyms
CG - Control Group
CNS - Central Nervous System
EG - Experimental Group
Extn - Extension
Flex - Flexion
INC - Inclination
L - Left
MS - Multiple sclerosis
PC - Pearson Correlation coefficients
R - Right
ROM - Range of Motion 


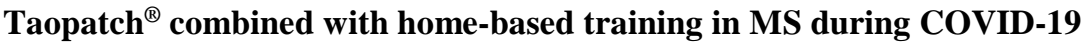

Eur J Transl Myol 31 (3): 9877, 2021 doi: 10.4081/ejtm.2021.9877

ROT - Rotation

$\mathrm{S}$ - Significances

$\mathrm{T}_{0}$ - Baseline

$\mathrm{T}_{1}$ - After Training period

TP - Training Program

\section{Authors contributions}

AA and PP conceptualization, writing; AA original draft preparation; PP, GM, AI, PR, DG, DK review and editing; KF, DG, FF data collection. All authors have approved the submitted version

\section{Acknowledgments}

We want to thank all the participants to study and also physical medicine and rehabilitation center "Vitality" from Vita, Sicily, Italy.

\section{Funding}

This research was conducted with PosturaLab ${ }^{\circledR}$ Italia funding.

\section{Conflict of Interest}

The authors declare no conflicts of interests.

\section{Ethical Publication Statement}

We confirm that we have read the Journal's position on issues involved in ethical publication and affirm that this report is consistent with those guidelines.

\section{Corresponding Author}

Giuseppe Messina, Department of Psychological, Pedagogical and Educational Sciences, Sport and Exercise Sciences Research Unit, University of Palermo, Italy. ORCID iD: 0000-0003-2774-49504

E-mail: giuseppe.messina17@unipa.it

\section{E-mail and ORCID iD of co-authors}

Alessandra Amato: alessandra.amato02@unipa.it ORCID iD: 0000-0002-6512-3840

Kaltrina Feka: kaltrina.feka92@gmail.com

ORCID iD: 0000-0003-1293-7995.

Diego Genua: genuaprofdiego@libero.it

ORCID iD: none

Paolo Ragonese: paolo.ragonese@unipa.it

ORCID iD: 0000-0003-2516-1567.

Dorota Kostrzewa-Nowak: dorota.kostrzewa-nowak@usz.edu.pl ORCID iD: 0000-0001-7025-3087.

Francesco Fischetti: francesco.fischetti@uniba.it ORCID iD: 0000-0001-8616-5372

Angelo Iovane: angelo.iovane@unipa.it

ORCID iD: 0000-0001-9945-6339.

Patrizia Proia: patrizia.proia@unipa.it ORCID iD: 0000-0002-0326-5560

\section{References}

1. Dobson R, Giovannoni G. Multiple sclerosis - a review. Eur J Neurol. 2019 Jan;26(1):27-40. doi: 10.1111/ene.13819. Epub 2018 Nov 18.
2. Karussis D. The diagnosis of multiple sclerosis and the various related demyelinating syndromes: a critical review. J Autoimmun. 2014 Feb-Mar;4849:134-42. doi: 10.1016/j.jaut.2014.01.022. Epub 2014 Feb 10.

3. Owens B. Multiple sclerosis. Nature. 2016 Nov 30;540(7631):S1. doi: 10.1038/540S1a..

4. Gross HJ, Watson C. Characteristics, burden of illness, and physical functioning of patients with relapsing-remitting and secondary progressive multiple sclerosis: a cross-sectional US survey. Neuropsychiatr Dis Treat. 2017 May 18;13:13491357. doi: 10.2147/NDT.S132079.

5. Proia P, Amato A, Puleo R, Arnetta F, Rizzo F, Di Grigoli L, Zangla D, Schirò G, Ragonese P, Messina G. Efficacy of 12 Weeks of Proprioceptive Training in Patients with Multiple Sclerosis. Journal of Human Sport and Exercise. 2019; 14 (5proc): S1986-S1992.

6. Kalichman L, Ben David C. Effect of selfmyofascial release on myofascial pain, muscle flexibility, and strength: A narrative review. J Bodyw Mov Ther. 2017 Apr;21(2):446-451. doi: 10.1016/j.jbmt.2016.11.006. Epub 2016 Nov 14.

7. Amato A, Messina G, Giustino V, Brusa J, Brighina F, Proia P. A pilot study on non-invasive treatment of migraine: The self-myofascial release. Eur $\mathrm{J}$ Transl Myol. 2021 Mar 26;31(1):9646. doi: 10.4081/ejtm.2021.9646.

8. Amorini AM, Nociti V, Petzold A, Gasperini C, Quartuccio E, Lazzarino G, Di Pietro V, Belli A, Signoretti S, Vagnozzi R, Lazzarino G, Tavazzi B. Serum lactate as a novel potential biomarker in multiple sclerosis. Biochim Biophys Acta. 2014 Jul;1842(7):1137-43. doi: 10.1016/j.bbadis.2014. 04.005. Epub 2014 Apr 13.

9. Lomeo A, Cacciaguerra G, Garsia D, Scolaro A. Utilisation des dispositifs nanotechnologiques dans les pathologies dégénératives cérébrales. Étude prospective sur 28 patients atteints de sclérose en plaques. Hegel. 2019:2:114, doi:10.4267/2042/ 70215.

10. Battaglia G. Influence of Occlusal Vertical Dimension on Cervical Spine Mobility in Sports Subjects. Acta Medica Mediterr. 2016; doi:10.19193/0393-6384_2016_5_135.

11. Battaglia G, Messina G, Giustino V, Zangla D, Barcellona M, Iovane A, Palma A. Influence of Vertical Dimension of Occlusion on Peak Force During Handgrip Tests in Athletes. Asian J Sports Med. 2018, In Press, doi:10.5812/asjsm.68274.

12. Burke JR, Papuga MO. Effects of foot orthotics on running economy: methodological considerations. J Manipulative Physiol Ther. 2012 May;35(4):32736. doi: 10.1016/j.jmpt.2012.04.001.

13. Carbonari B, Balducci F, Cesaretti G, Cesanelli L, Botticelli D, Messina G. Performance, balance and posture variations with Occlusal Splint and 
Taopatch ${ }^{\circledR}$ devices: a retrospettive cross-over study. J Sports Med Phys Fitness. 2021 Feb;61(2):317323. doi: 10.23736/S0022-4707.20.11053-3. Epub 2020 Jul 30.

14. Cataldi S, Francavilla VC, Bonavolontà V, De Florio O, Carvutto R, De Candia M, Latino F, Fischetti F. Proposal for a Fitness Program in the School Setting during the COVID 19 Pandemic: Effects of an 8-Week CrossFit Program on Psychophysical Well-Being in Healthy Adolescents. Int J Environ Res Public Health. 2021 Mar 18;18(6):3141. doi: 10.3390/ijerph18063141.

15. Hebisz P, Hebisz R, Murawska-Ciałowicz E, Zatoń $M$. Changes in exercise capacity and serum BDNF following long-term sprint interval training in welltrained cyclists. Appl Physiol Nutr Metab. 2019 May;44(5):499-506. doi: 10.1139/apnm-20180427. Epub 2018 Oct 4.

16. Kim M, Lee M, Kim M, Oh S, Jung S, Yoon B. Effectiveness of therapeutic inflatable ball selfexercises for improving shoulder function and quality of life in breast cancer survivors after sentinel lymph node dissection. Support Care Cancer. 2019 Jul;27(7):2349-2360. doi: 10.1007/s00520-019-4656-0. Epub 2019 Mar 12.

17. L Liu K, Zhou Y, Xie W, Gu Z, Jin Y, Ye X, Chen $\mathrm{X}$, Fan B, Wang H, Cui Y. Handgrip exercise reduces peripherally-inserted central catheterrelated venous thrombosis in patients with solid cancers: A randomized controlled trial. Int J Nurs Stud. 2018 Oct;86:99-106. doi: 10.1016/j.ijnurstu.2018.06.004. Epub 2018 Jun 22.

18. Amato A, Messina G, Giustino V, Brusa J, Brighina F, Proia P. A pilot study on non-invasive treatment of migraine: The self-myofascial release. Eur J Transl Myol. 2021 Mar 26;31(1):9646. doi: 10.4081/ejtm.2021.9646. PMID: 33709650; PMCID: PMC8056163.

19. Fritz NE, Newsome SD, Eloyan A, Marasigan RE, Calabresi PA, Zackowski KM. Longitudinal relationships among posturography and gait measures in multiple sclerosis. Neurology. 2015 May 19;84(20):2048-56. doi: 10.1212/WNL. 0000000000001580. Epub 2015 Apr 15.

20. Malchiodi Albedi G, Corna S, Aspesi V, Clerici D, Parisio C, Seitanidis J, Cau N, Brugliera L, Capodaglio P. Effects of nanotechnology-based devices on postural control in healthy subjects. J Sports Med Phys Fitness. 2018 Oct;58(10):14181422. doi: 10.23736/S0022-4707.17.07530-2. Epub 2017 Sep 5.

21. Chen G, Ågren H, Ohulchanskyy TY, Prasad PN. Light upconverting core-shell nanostructures: nanophotonic control for emerging applications. Chem Soc Rev. 2015 Mar 21;44(6):1680-713. doi: 10.1039/c4cs00170b.

22. Lamers I, Kerkhofs L, Raats J, Kos D, Van Wijmeersch B, Feys P. Perceived and actual arm performance in multiple sclerosis: relationship with clinical tests according to hand dominance. Mult Scler. $2013 \quad$ Sep;19(10):1341-8. doi: 10.1177/1352458513475832. Epub 2013 Feb 13.

23. Gordon NM, Rudroff T, Enoka JA, Enoka RM. Handedness but not dominance influences variability in endurance time for sustained, submaximal contractions. J Neurophysiol. 2012 Sep;108(5):1501-10. doi: 10.1152/jn.01144.2011. Epub 2012 Jun 13.

24. Severijns D, Lamers I, Kerkhofs L, Feys P. Hand grip fatigability in persons with multiple sclerosis according to hand dominance and disease progression. J Rehabil Med. 2015 Feb;47(2):15460. doi: 10.2340/16501977-1897.

25. Schwid SR, Goodman AD, McDermott MP, Bever CF, Cook SD. Quantitative functional measures in MS: what is a reliable change? Neurology. 2002 Apr 23;58(8):1294-6. doi: 10.1212/wnl.58.8.1294.

26. Iyengar V, Santos MJ, Ko M, Aruin AS. Grip force control in individuals with multiple sclerosis. Neurorehabil Neural Repair. 2009 Oct;23(8):85561. doi: 10.1177/1545968309338194. Epub 2009 Jun 16.

27. Messina G, Amato A, Brighina F, Lo Monaco A, Giustino V, Brusa J, Iovane A, Proia P. Lactate Level and Handgrip Test in Migraine and Fibromyalgia after Self-Myofascial Release Treatment. Journal of Human Sport and Exercise. 2019 14(5proc), S2019-S2025. doi: 10.14198 /jhse.2019.14.Proc5.23

28. Newsome SD, von Geldern G, Shou H, Baynes M, Marasigan RER, Calabresi PA, Zackowski KM. Longitudinal assessment of hand function in individuals with multiple sclerosis. Mult Scler Relat Disord. 2019 Jul;32:107-113. doi: 10.1016/j.msard.2019.04.035. Epub 2019 May 6.

29. Barrett LE, Cano SJ, Zajicek JP, Hobart JC. Can the ABILHAND handle manual ability in MS? Mult Scler. 2013 May;19(6):806-15. doi: 10.1177/1352458512462919. Epub 2012 Oct 24.

Submission: May 252021

Revision received: June 22, 2021 Accepted for publication: August 4, 2021 